J. Clin. Chem. Clin. Biochem.

Vol. 25, 1987, pp. 737-741

(C) 1987 Walter de Gruyter \& Co. Berlin · New York

\title{
Further Studies on the Standardization of Neonatal Bilirubin
}

\author{
By B. G. Blijenberg, H. A. Roetering, A. de Vos and B. Leijnse \\ Department of Clinical Chemistry, Academic Hospital Rotterdam-Dijkzigt, The Netherlands
}

(Received April 18/July 3, 1987)

Summary: Certain problems in the standardization of direct-reading instruments (bilirubinometers) were investigated. It was shown that the combination of wavelength setting and choice of $\mathrm{pH}$ is very important with respect to the standard to be used. It is emphasized that in fact there is no synthetic bilirubin standard which can be used as primary standard. Reasons are given why the only pragmentic solution proved to be a pool of neonatal serum.

\section{Introduction}

In a previous publication we discussed the mediocre results seen in surveys on neonatal bilirubin (1). A lack of valid standardization procedures was shown to be an important contributing factor in the variation of results.

Our study has placed some emphasis on the calibration of so-called direct-reading instruments (bilirubinometers) because these are used widely. We came to the frustrating conclusion that an accurate standard did not seem to exist, and that only a pragmatic solution could be applied.

We felt the need for a new study because we could find no explanation for the differences between serum and albumin-based standards when applied to measurements by direct-reading. Variation in wavelength setting and $\mathrm{pH}$ of the serum sample can be expected to have substantial influence on the measurement of the total bilirubin concentration $(2-4)$.

\section{Materials and Methods}

The same materials and methods were used as in our previous article; briefly:

\section{Materials}

1. Neonatal serum samples stored at $-20^{\circ} \mathrm{C}$ before use

2. Adult serum samples

3. Bilirubin (Pfanstiehl)

4. Human albumin (Behringwerke AG)

5. Bilirubin reference preparations (Dutch National Institute of Public Health)

6. Bilirubin-Control (Dade)

7. Precibil (Boehringer Mannheim)

8. Ultimate C20 (Beckman)

9. Kontrollogen (Behringwerke AG)

10. Controbil (Merck)

Materials 6, 7, 8 and 9 are of human origin while materials 5 and 10 are bovine.

\section{Methods}

Here too, the reader is referred to our previous article i.e. the candidate reference method checked as described.

The spectrophotometer used was a Beckman model 25 with a diffraction grating as dispersing element.

The direct-reading measurements in our spectrophotometer were carried out with plane Hellma micro cuvettes with an optical path length of $1.00 \mathrm{~mm}$, giving absorbance values ranging from 0.500 to 1.500 .

We used on O'Hara Bilirubinometer Model III. All serum samples were filtered using a filter needle (filter rating $5 \mu \mathrm{m}$ ).

Terminology

Direct reading in this study means that the absorbance of the sample is measured without dilution. 


\section{Results}

Through the courtesy of the Dutch representative, an O'Hara Bilirubinometer type BB-III, a direct-reading instrument for the determination of total bilirubin in neonatal serum, was placed at our disposal. The measuring wavelengths are 455 and $575 \mathrm{~nm}(6,7)$. In figure 1 the results are displayed from two sets of experiments. In one set the bilirubinometer was calibrated exactly according to the instructions of the manufacturer and the representative, while in the second set we used our own human serum-based calibrator prepared according to the description of Doumas et al. (5).

We then calibrated the instrument with the same commercial sera as used in our previous article (1). The results of the measurements of one neonatal serum pool varied between 164 and $179 \mu \mathrm{mol} / \mathrm{l}$.

We started the study by drawing a number of spectra of various bilirubin standards. In figure 2 the spectra of serum and albumin based standards are given, while figure 3 shows the spectra of some commercial bilirubin preparations.

The spectral shifts shown in figure 3 were assumed to be caused by differences in $\mathrm{pH}$ of the sera analysed ( $\mathrm{pH}$-data given in the legend). Therefore we decided in the next experiment to vary the $\mathrm{pH}$ of the bilirubin

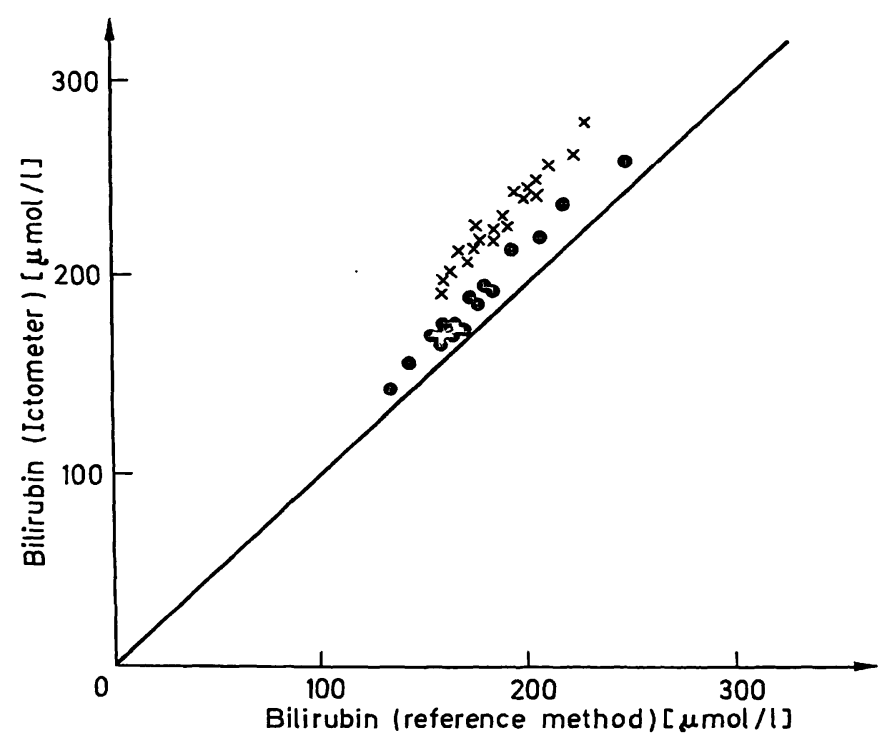

Fig. 1. Comparison of bilirubinometer results with reference method values

$x$ bilirubinometer calibrated according instructions of the manufacturer

$\mathrm{n}=20, \mathrm{x}=188 \mu \mathrm{mol} / \mathrm{l}, \mathrm{y}=229 \mu \mathrm{mol} / \mathrm{l}$

- bilirubinometer calibrated with home-made human serum bilirubin preparation

$\mathrm{n}=17, \mathrm{x}=178 \mu \mathrm{mol} / \mathrm{l}, \mathrm{y}=229 \mu \mathrm{mol} / \mathrm{l}$

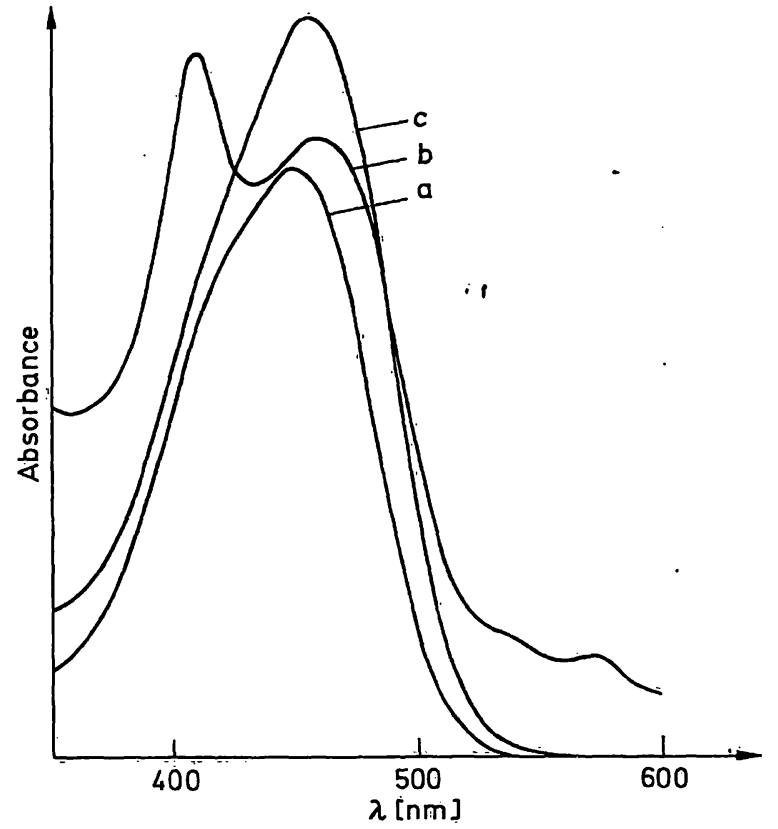

Fig. 2. The influence of the matrix on the bilirubin spectrum. All solutions were at $\mathrm{pH} 8.4$

Spectrum $a \equiv$ bilirubin in human albumin $(40 \mathrm{~g} / \mathrm{l})$

Spectrum $b=$ bilirubin in adult serum

Spectrum $\mathrm{c}=$ neonatal serum sample

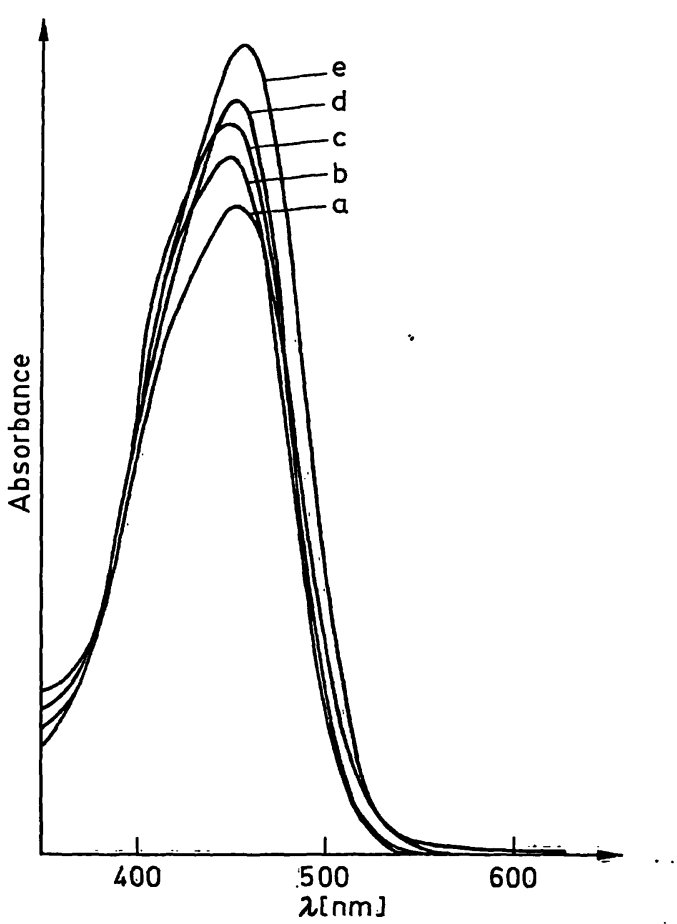

Fig. 3. Spectra of some commercial bilirubin preparations. Spectrum a $=$ Precibil $(\mathrm{pH} \rightleftharpoons 9.6)$,

peak at $458 \mathrm{~nm}$

Spectrum $b=$ Kontrollogen $(\mathrm{pH}=7.8)$, peak at $455 \mathrm{~nm}$

Spectrum c = Ultimate $\mathrm{C} 20(\mathrm{pH}=.8 .3)$, peak at $454 \mathrm{~nm}$

Spectrum $\mathrm{d}=$ Bilirubin-Control $(\mathrm{p} \dot{\mathrm{H}} \stackrel{\mathrm{P}}{=} 8.3$ ),

Spectrum $\mathrm{e}=$ Controbil $(\mathrm{p} \overline{\mathrm{H}}=7.5)$, peak at $459 \mathrm{~nm}$ peak at 463 nim

J. Clin. Chem. Clin. Biochem. / Vol. 25, 1987/ No. 10 


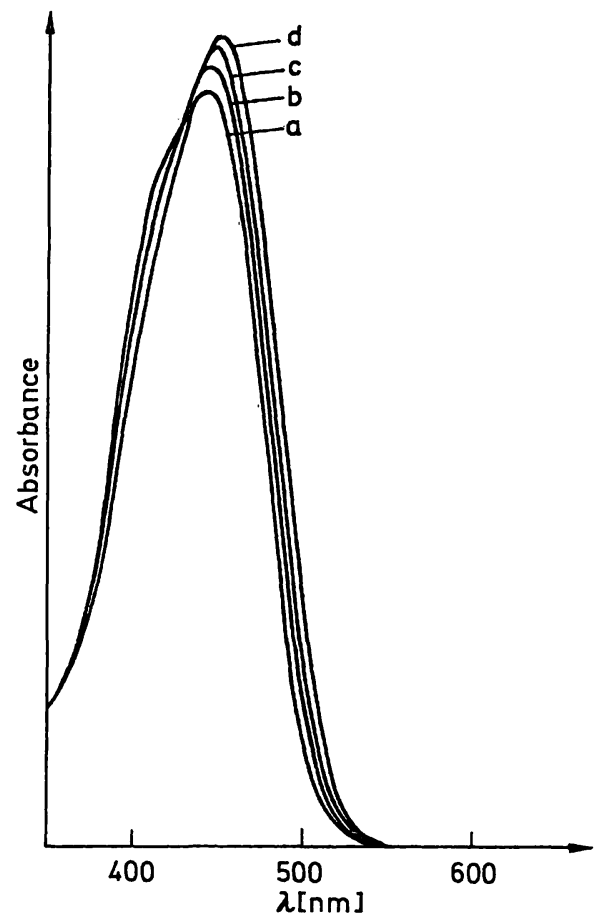

Fig. 4. The influence of $\mathrm{pH}$ on the bilirubin spectrum Spectrum $\mathrm{a}-\mathrm{pH}=6.8$

Spectrum b $-\mathrm{pH}=7.5$

Spectrum c $-\mathrm{pH}=8.0$

Spectrum $\mathrm{d}-\mathrm{pH}=8.6$

solution. In figure 4 the spectra of some albuminbased bilirubin solutions in dependency of the $\mathrm{pH}$ are given.

Serum-based standards proved to give comparable spectral shifts.

To avoid misinterpretation of direct-reading results when compared with those obtained by applying the candidate reference method (5), we studied the influence of $\mathrm{pH}$ on the latter method. The data are given in table 1.

Tab. 1. The influence of the $\mathrm{pH}$ of the bilirubin standard on the reference method values.

\begin{tabular}{lll}
\hline Protein matrix & $\mathrm{pH}$ & $\begin{array}{l}\text { Reference method } \\
(\mu \mathrm{mol} / \mathrm{l})\end{array}$ \\
\hline Albumin $(40 \mathrm{~g} / \mathrm{l})$ & 6.59 & 282 \\
& 7.01 & 280 \\
& 7.58 & 281 \\
& 8.00 & 274 \\
& 8.55 & 280 \\
Serum & 8.96 & 277 \\
& 6.59 & 283 \\
& 7.12 & 287 \\
& 7.60 & 285 \\
& 8.05 & 280 \\
& 8.43 & 286 \\
\hline
\end{tabular}

The experiments described in our previous publication were done with neonatal serum samples stored in the refrigerator, mostly pooled. Measurement of the $\mathrm{pH}$ of 40 of those samples gave an average value of 8.51 with a range from 7,86 to 8.96 .

One obvious conclusion could be drawn from all experiments, i. e. it seemed useful to repeat our earlier study with the addition of standardization at $\mathrm{pH}=8.5$.

Two bilirubin standard solutions, one based on human serum and one on human albumin, were divided into two parts. One part was adjusted to $\mathrm{pH}=7.4$, the other to $\mathrm{pH}=8.5$. All standards having bilirubin concentrations of $200-250 \mu \mathrm{mol} / \mathrm{l}$, were analysed in triplicate by two technicians, using the candidate reference method. The average values were used as set-points for the direct-reading experiments performed afterwards. Here the absorbances of 19 neonatal serum samples were measured at 455 and $575 \mathrm{~nm}$. All calculations are given in table 2.

Tab. 2. The influence of the matrix of the standard in the direct-reading technique.

The various standard solutions and the neonatal sera were estimated by the candidate reference method.

The absorbance readings of the bilirubin preparations and the 19 neonatal sera were taken at 455 and $575 \mathrm{~nm}$.

Calculation formulae:

$$
\begin{aligned}
\text { a. } c(\text { sample })= & \frac{\left(\mathrm{A}_{455}-\mathrm{A}_{575}\right) \text { sample }}{\mathrm{A}_{455}(\text { standard })-\mathrm{A}_{455}(\text { blank })} \\
& \times[c \text { (standard })-c \text { (blank) }] \mu \mathrm{mol} / 1 \\
\text { b. } c(\text { sample })= & \frac{\left(\mathrm{A}_{455}-\mathrm{A}_{575}\right) \text { sample }}{\left(\mathrm{A}_{455}-\mathrm{A}_{575}\right) \text { standard }} \\
& \times c \text { (standard } \mu \mathrm{mol} / 1
\end{aligned}
$$

Average results of 19 neonatal sera in $\mu \mathrm{mol} / \mathrm{l}$.

Between brackets: percentage difference from reference method value.

\begin{tabular}{lll} 
& calc. a & calc. b \\
\hline Serum $\mathrm{pH}=7.4$ & $194(18)$ & $188(15)$ \\
Serum $\mathrm{pH}=8.5$ & $187(14)$ & $177(8)$ \\
Albumin $\mathrm{pH}=7.4$ & $199(21)$ & $199(21)$ \\
Albumin $\mathrm{pH}=8.5$ & $189(15)$ & $189(15)$ \\
\hline
\end{tabular}

Spectral deviations can also occur if the measurements are not performed at the correct wavelengths. Therefore we were interested to know whether the interference filters used in direct-reading instruments were correct. With the cooperation of colleagues, it was possible to measure the transmission maxima of the filters in their instruments. The data are shown in table 3. 
Tab. 3. Transmission maxima of the 455 and the $575 \mathrm{~nm}$ interference filters of some bilirubinometers.

$$
\text { Ratio }=\frac{\text { absorptivity peak } \mathrm{HbO}_{2} 455 \mathrm{~nm} \text { measured* }}{\text { absorptivity peak } \mathrm{HbO}_{2} 575 \mathrm{~nm} \text { measured }}
$$

\begin{tabular}{llll} 
Instrument & $455 \mathrm{~nm}$ & $575 \mathrm{~nm}$ & Ratio \\
\hline 1 & $456 \mathrm{~nm}$ & $575 \mathrm{~nm}$ & 0.85 \\
2 & $457 \mathrm{~nm}$ & $579 \mathrm{~nm}$ & 0.84 \\
3 & $453 \mathrm{~nm}$ & $580 \mathrm{~nm}$ & 1.00 \\
4 & $453 \mathrm{~nm}$ & $584 \mathrm{~nm}$ & 1.42 \\
5 & $456 \mathrm{~nm}$ & $583 \mathrm{~nm}$ & 1.14 \\
6 & $457 \mathrm{~nm}$ & $576 \mathrm{~nm}$ & 0.81 \\
7 & $452 \mathrm{~nm}$ & $575 \mathrm{~nm}$ & 0.99
\end{tabular}

* For the absorptivity values of the various wavelengths see references 8 and 9.

\section{Discussion}

All experiments, that is to say, the spectrophotometric as well as the bilirubinometer experiments, give the impression that it is not possible to calibrate direct-reading techniques, except by using neonatal serum specimens.

The starting point of this study was the hope, that by extending and modifying the experimental design of our previous work, we would find an explanation for the differences described. In this respect we were successful to a certain extent. From table 2 it is clear that by changing the $\mathrm{pH}$ of the standard solutions from 7.4 to 8.5 a considerable improvement was obtained when comparing the direct-reading results with the reference method results. This means, mutatis mutandis, that in the actual situation one should have a calibrator with $\mathrm{pH}=7.4$. For an explanation of the calculation it is useful to consider in detail the nature of the absorbance measurements at 455 and $575 \mathrm{~nm}$. As published earlier $(2,3)$ the light absorption at these wavelengths must be attributed mainly to bilirubin (conjugated and unconjugated), oxyhaemoglobin, carotenoids, methaemalbumin, transferrin and turbidity. In our setting turbidity can be dismissed, because we filtered the serum samples. Furthermore bilirubin is assumed to be unconjugated. Thus, the following formulae apply:

formula 1:

$$
\begin{aligned}
\mathrm{A}(\text { sample })=\mathrm{A}(\text { bilirubin }) & +\mathrm{A}(\text { haemoglobin }) \\
& +\mathrm{A} \text { (rest) }
\end{aligned}
$$

formula 2:

$$
\begin{aligned}
\mathrm{A}(\text { rest })=\mathrm{A}(\text { carotenoids }) & +\mathrm{A} \text { (methaemoglobin }) \\
& +\mathrm{A}(\text { transferrin }) .
\end{aligned}
$$

These formulae are applicable to both wavelengths 455 and $575 \mathrm{~nm}$. An advantage of our spectrophotometric method over the use of a bilirubinometer is that we can measure accurately a standard blank absorbance, i.e. a real blank of the protein base of the standard can be measured. Therefore we are able to apply two methods of calculation to compensate for background absorbance: subtraction of the absorbance of the blank at $455 \mathrm{~nm}$ from the absorbance of the standard; and subtraction of the absorbance of the standard at $575 \mathrm{~nm}$. The formulae for these two methods are:

formula 3:

$$
\begin{aligned}
& c(\text { sample })=\frac{\left(\mathrm{A}_{455}-\mathrm{A}_{575}\right) \text { sample }}{\mathrm{A}_{455}(\text { standard })-\mathrm{A}_{455}(\text { blank })} \\
& \text { and } \\
& \quad \times[c \text { (standard })-c \text { (blank })] \mu \mathrm{mol} / \mathrm{l}
\end{aligned}
$$

formula 4:

$$
\begin{aligned}
c(\text { sample })= & \frac{\left(\mathrm{A}_{455}-\mathrm{A}_{575}\right) \text { sample }}{\left(\mathrm{A}_{455}-\mathrm{A}_{575}\right) \text { standard }} \\
& \times c(\text { standard }) \mu \mathrm{mol} / 1,
\end{aligned}
$$

where $c$ (standard) and $c$ (blank) can be established by means of the candidate reference method.

As already stated, background correction with a blank can only be performed with a standard. Therefore formula 3 seems to be the better one. However, formula 4 forms the basis of bilirubinometers. This is the crucial point in our study, because by applying formula 4 the absorbance values given in formulae 1 and 2 are included. Then we make three errors which compensate each other partly:

a) the molar absorbancies of oxyhaemoglobin differ between 455 and $575 \mathrm{~nm}, A_{575}$ being the higher one $(8,9)$

b) the absorbance value of carotenoids, methaemoglobin and transferrin are higher at $455 \mathrm{~nm}$ than at $575 \mathrm{~nm}$ (3)

c) the oxyhaemoglobin content in neonatal sera can vary considerably and is certainly much higher than in the adult serum sample used for making the standard (10) and furthermore the carotenoid, methaemoglobin and transferrin contents are generally much lower in neonatal sera than in the adult sera used in serum standards.

In view of these errors, it is not surprising that both calculations (formulae 3 and 4) for albumin standards give similar results. Comparison of assays using the serum and albumin-based standards shows comparable values for percentage differences from the reference method value, i.e. $8 / 21 \%$ and $14 / 15 \%$ (serum standard/albumin standard) at $\mathrm{pH} 7.4$ and 8.5 , re- 
spectively (tab. 2). To demonstrate the effects of various filter combinations on the results (tab. 3), we used one neonatal serum sample, applying formula 4 to the absorbances values at the two wavelengths. The lowest and highest bilirubin concentrations differed by $3 \%$.

In summary, the reasons for the variation in results of direct-reading neonatal bilirubin measurements seen in surveys are now apparent. The variations are due to:

1. possible errors in bilirubin data of commercial standard solutions (1)

2. the impossibility of making an accurate bilirubin standard because of matrix problems

3. spectral shifts caused by differences in $\mathrm{pH}$ and filter combinations.

This may sound very negative. Perhaps the spectral effects in the direct-reading instruments are less severe than indicated by our results. Moreover, it is possible to be practical because clinical decisions are generally not based on one bilirubin measurement. In our opinion it is best to collect a neonatal serum pool as a kind of a masterpool. The total bilirubin content of this pool is measured with the candidate reference method. The value found is used as primary standard in the direct-reading instrument against which a larger home-made serum pool or commercial sample can be calibrated. These samples can act as secondary standards.

For this purpose, the protein matrix does not matter, despite the spectral differences that we measured (see fig. 2). Thus, human serum as well as human albumin can be used.

Nevertheless, it is an illusion to think that a directreading technique can replace the reference method. It has practical value only provided that there is a well-defined calibration procedure (like the proposed one) and an acceptable quality assessment scheme.

\section{Acknowledgement}

Thanks are due to:

1. Dr. J. C. Koedam (Dutch Institute of Public Health, Bilthoven) for providing the control materials.

2. Drs. C. P. Modder (Van Dam - Bethesda Ziekenhuis, Rotterdam) for his help in the collection of specimens.

3. Meyvis Instruments (Bergen op Zoom) for providing the bilirubinometer.

4. Dr. G. Röhle (Deutsche Gesellschaft für Klinische Chemie, Bonn) for providing some control materials.

5. Mrs. A. P. Copper-Staamer for her skilfull clerical assistance in preparing the manuscript.

\section{References}

1. Blijenberg, B. G., Roetering, H. A. \& Leijnse, B. (1987) J. Clin. Chem. Clin. Biochem. 25, 177-181.

2. Turnell, D. C. (1985) Ann. Clin. Biochem. 22, 217-221.

3. Hertz, H., Dybkaer, R. \& Lauritzen, M. (1974) Scand. J. Clin. Lab. Invest. 33, 215-230.

4. Bijster, P., Vader, H. L. \& Vink, C. L. J. (1981) Ann. Clin. Biochem. 18, 102-105.

5. Doumas, B. T., Kwok-Cheun, P. P., Perry, B. W., Jendrzejezak, B., McComb, R. B., Schaffer, R. \& Hause, L. L. (1985) Clin. Chem. 31, 1779-1789.
6. Stein, S. M., McKinley, I., Horn, D. B. \& Keay, A. J. (1974) Clin. Chim. Acta 54, 107-113.

7. Schütz, D. \& Gerstheimer, A. (1976) Klin. Pädiat. 188, 62-66.

8. Ziwart, A., Van Kampen, E. J. \& Zijlstra, W. G. (1986) Clin. Chem. 32, 972-978.

9. Zwart, A. Personal communication.

10. Blijenberg, B. G., Brouwer, H. J. \& Leijnse, B. (1978) J. Clin. Chem. Clin. Biochem. 16, 425-428.

11. Wissenschaftliche Tabellen Geigy (1977) Ciba-Geigy A. G., Basel.
Dr. B. G. Blijenberg

Department of Clinical Chemistry

Academic Hospital Rotterdam-Dijkzigt

Dr. Molewaterplein 40

NL-3015 GD Rotterdam 
- 